\title{
Inquérito soroepidemiológico para os vírus influenza em Belém, Pará, Brasil, 1992-1993
}

\author{
Seroepidemiological survey for influenza virus \\ in Belém, Pará, Brazil, 1992-1993
}

Domingos Ezenildo Matos dos Santos 1

Cláudia Alessandra da Silva Cardias 2

Wyller Al encar de Mello 2

\footnotetext{
1 Laboratório de Virologia, Departamento de Patologia, Centro de Ciências Biológicas, Universidade Federal do Pará. Rua Augusto Corrêa s/n, Campus Universitário do Guamá, Belém, PA 66075-110, Brasil. 2 Instituto Evandro Chagas. Av. Almirante Barroso 492, C. P. 621, Belém, PA 66090-000, Brasil.
}

Abstract A seroepidemiological study was carried out from 1992 to 1993 to estimate the prevalence of antibody to prevailing influenza virus strains circulating among patients attending the IEC Virology Laboratory in Belem, Northern Brazil. A total of 179 (11\%) of serum samples were obtained during the post-epidemic period and processed by the hemagglutination inhibition test against the A/Tai wan/1/86 (H1N1), A/Beijing/353/89 (H3N2), and B/Yamagata/16/88 types of influenza virus. The serological results indicate circulation of viruses antigenically related to all three strains during the two-year study period. In 1992, the overall prevalence rates of $\mathrm{HI}$ antibodies to $\mathrm{H} 1 \mathrm{~N} 1$ and $\mathrm{H} 3 \mathrm{~N} 2$ were $84 \%$ and $56 \%$, respectively. Presence of anti bodies to both strains was detected in all age groups, suggesting intense viral activity that year. Antibodies to influenza B were detected at lower levels in all patients during this period. Similar prevalence to the HIN 1 virus was noted in 1993, indicating that this strain occurred in both years. However, an increase in prevalence rates for the H3N2 virus was seen in 1993, suggesting that this strain (or a related virus) circulated intensively during this year. Influenza B activity also increased in 1993, causing infection mainly among young adults.

Key words Epidemiology; Seroprevalence; Influenza Strains

Resumo Um estudo soroepidemiológico foi realizado para determinar a prevalência de anticorpos IH para os sorotipos de influenza circulantes entre pacientes atendi dos no Laboratório de Virologia do IEC, em Belém, PA, Brasil , em 1992 e 1993. Um total de 179 (11\%) amostras de sangue foi col etado durante período pós-epi dêmi co e processado pel o teste da I ni bição da Hemaglutinação para os vírus da influenza A/Tai wan/1/86 (H1N1), A/Beijing/353/89 (H3N2) e B/Yamagata/16/88. Os resultados indicaram a circulação de vírus antigeni camente relacionados aos três soroti pos pesqui sados. Em 1992, al tas taxas de soropositividade foram observadas para as cepas H 1N 1 (84\%) e H3N2 (56\%), bem como anticorpos IH foram detectados em todas as faixas de idade, sugerindo intensa circulação desses vírus. No mesmo ano, a atividade da influenza B revelou-se em níveis moderados. A prevalência de anticorpos IH para os vírus H1N1, em 1993, foi similar à observada em 1992, indicando a circulação desses vírus em ambos os anos. Um aumento na prevalência dos vírus H3N2, em 1993, sugere que a cepa A/Beijing/353/89 (ou uma antigenicamente relacionada) também circulou intensamente naquele ano. Do mesmo modo, a atividade dos vírus da influenza B aumentou em 1993, como apontam as infecções em todas as idades, particularmente entre os adultos jovens.

Palavras-chave Epidemiologia; Soroprevalência; Vírus Influenza 


\section{Introdução}

A gripe é uma síndrome específica do trato respiratório causada principalmente pelos vírus da influenza A e B. Esses patógenos acometem pessoas de todas as idades e se caracterizam por uma notável variabilidade antigênica, o que Ihes possibilita constituir, a cada dois a três anos, cepas virais antigenicamente distintas, do que resulta a infecção dos indivíduos suscetíveis. Por outro lado, estudos imunológicos desenvolvidos para determinar níveis de anticorpos inibidores da hemaglutinação, capazes de exercer proteção contra reinfecções após contato recente com o vírus da influenza, concluíram que títulos iguais ou superiores a 1/40 conferem imunidade (Jennings et al., 1985; Zuckerman et al., 1991).

Por serem vírus de fácil transmissão, não existem barreiras geográficas que impeçam a ocorrência de extensas epidemias. Nesse sentido, a Organização Mundial de Saúde tem empreendido esforços para monitorar a magnitude dos surtos ocorridos, assim como a morbimortalidade concernente à emergência de novas variantes anti gências virais (Chakraverti et al., 1986).

A determinação de prevalência da gripe é estabelecida diretamente através do isolamento viral e, indiretamente, a partir das taxas de morbidade e mortalidade relativas às doenças respiratórias agudas (Stuart-Harris, 1979), bem como pelo estudo sorológico.

Nos países onde os indicadores epidemiológicos não são confiáveis, e na ausência de isolamento viral, a avaliação sorológica representa um instrumento fundamental na vigilância epidemiológica do vírus da influenza, por informar acerca do nível de imunidade nos indivíduos e avaliar o impacto de um surto epidêmico na população (Candeias \& Pereira, 1972; McGregor et al., 1979).

No Brasil, segundo Takimoto et al. (1986), poucas investigações soroepidemiológicas são regularmente desenvolvidas, visando a mapear os subtipos virais de influenza prevalentes na população.

O presente estudo abrange a magnitude da resposta imune frente à infecção pelos subtipos dos vírus da influenza A/Taiwan/1/ 86 (H1N1), A/Beijing/353/89 (H3N2) e B/Yamagata/ 16/88, circulantes entre a população atendida no serviço médico de Virologia do Instituto Evandro Chagas (IEC), em Belém-PA, caracterizando a sua distribuição por faixa etária, a par de estimar, em bases sorológicas, a extensão da epidemia no período em questão.
Material e métodos

$\underline{\text { Material }}$

Coletou-se um total de 179 amostras de sangue (82 colhidas em 1992 e 97 durante 1993), equivalente a $11 \%$ da população assistida no serviço médico de Virologia do IEC, durante o período pós-epidêmico (novembro-dezembro) de cada ano, para o diagnóstico de outras patologias que não respiratória. As amostras foram obtidas de indivíduos pertencentes a ambos os sexos ( 83 mulheres e 96 homens), com idades entre zero e 75 anos e nível sócio-econômico predominantemente baixo. Após a coleta do sangue por punção venosa, os soros eram estocados a $-20^{\circ} \mathrm{C}$ até a realização dos testes, a qual ocorreu no segundo semestre de 1994.

$\mathrm{Na}$ composição das amostragens, procurou-se reunir números comparáveis de espécimens por faixa etária e ano, o que foi possível até o grupamento de 25 a 59 anos de idade.

\section{Método laboratorial}

A metodologia laboratorial de diagnóstico consistiu no teste da Inibição da Hemaglutinação $(\mathrm{IH})$, que se baseia em bloquear a propriedade hemaglutinante dos vírus influenza. É um teste de fácil execução e de boa sensibilidade, muito utilizado para identificar os padrões virais da influenza (Chakraverty, 1980; Wood et al., 1994).

O procedimento técnico, de acordo com as instruções recomendadas no CDCP (1991), envolveu o tratamento prévio das amostras de soro com enzima destruidora de receptores "RDE", dotada de atividade inibidora da hemaglutinação inespecífica. Os antígenos, anti-soros e a enzima destruidora de receptores (RDE) foram doados pelo "Centers for Disease Control and Prevention" (Atlanta - Georgia, EUA).

A titulação dos antígenos-padrão (A/Taiwan/ 1/ 86, A/Beijing/353/ 89 e B/Yamagata/ 16/88) foi executada pela técnica da Hemaglutinação (HA) para determinar as quatro unidades hemaglutinantes, precedendo a realização dos testes de IH. Outra HA era efetuada ao término daqueles testes para checar a estabilidade dos antígenos empregados.

Foram considerados positivos os soros que apresentaram títulos de anticorpos IH com valores iguais ou superiores a $1 / 20$.

\section{Método estatístico}

Utilizou-se o teste do $\chi^{2}$ (Qui-Quadrado) para estabelecer as diferenças estatisticamente significantes entre as respostas positivas observa- 
Tabela 1

Distribuição por faixa etária e ano da freqüência de soropositividade, pela inibição da hemaglutinação para $A / T a i w a n / A / 86$ (H1N 1), A/Beijing/353/89 (H3N2) e B/Yamagata/16/88, em Belém, PA.

\begin{tabular}{|c|c|c|c|c|c|c|c|c|c|c|c|c|}
\hline \multirow[t]{2}{*}{ Faixa etária (anos) } & \multicolumn{2}{|c|}{$0-4$} & \multicolumn{2}{|c|}{$5-14$} & \multicolumn{2}{|c|}{$15-24$} & \multicolumn{2}{|c|}{$25-39$} & \multicolumn{2}{|c|}{$\geq 60$} & \multicolumn{2}{|c|}{ Total } \\
\hline & POS & $\%$ & POS & $\%$ & POS & $\%$ & POS & $\%$ & POS & $\%$ & POS & $\%$ \\
\hline 1992 & \multicolumn{2}{|c|}{19} & \multicolumn{2}{|c|}{18} & \multicolumn{2}{|c|}{20} & \multicolumn{2}{|c|}{20} & \multicolumn{2}{|c|}{05} & \multicolumn{2}{|c|}{82} \\
\hline H1N 1 & 12 & 63 & 16 & 89 & 20 & 100 & 16 & 80 & 05 & 100 & 69 & 84 \\
\hline $\mathrm{H} 3 \mathrm{~N} 2$ & 06 & 31 & 14 & 77 & 14 & 70 & 09 & 45 & 03 & 60 & 46 & 56 \\
\hline 1993 & \multicolumn{2}{|c|}{20} & \multicolumn{2}{|c|}{17} & \multicolumn{2}{|c|}{20} & \multicolumn{2}{|c|}{20} & \multicolumn{2}{|c|}{20} & \multicolumn{2}{|c|}{97} \\
\hline H1N 1 & 13 & 65 & 15 & 88 & 20 & 100 & 10 & 90 & 13 & 65 & 79 & 81 \\
\hline $\mathrm{H} 3 \mathrm{~N} 2$ & 09 & 45 & 11 & 65 & 20 & 100 & 16 & 80 & 18 & 90 & 74 & 76 \\
\hline B/YAM & 04 & 20 & 11 & 65 & 15 & 75 & 11 & 55 & 10 & 50 & 51 & 52 \\
\hline
\end{tabular}

das em cada grupo etário em função do ano estudado, na distribuição da resposta imune ao longo dos dois anos, e o predomínio de títulos iguais ou maiores a $1 / 40$.

A análise estatística para o ano de 1992 não incluiu a faixa etária de sessenta anos ou mais, devido ao número reduzido de indivíduos nesta categoria. Este fato foi também considerado quando se determinou a distribuição das taxas de positividade entre os dois anos, de modo que compararam-se somente as classes etárias de zero a 59 anos.

\section{Resultados}

Os resultados sorológicos para a cepa A/Taiwan/1/86 (H1N1) alcançaram aproximadamente 84\% (69/82) em 1992, e 81\% (79/97) em 1993. Nesses anos, as respostas imunes predominaram entre os adultos jovens ( 15 a 24 anos), com positividade de $100 \%$ (20/20). Por outro lado, revelaram-se prevalências acima de $60 \%$ nas demais faixas etárias (Tabela 1 ).

As prevalências de anticorpos I H para a cepa A/Beijing/353/89 (H3N2) foram de 56\% (46/ 82) em 1992 e 76\% (74/97) em 1993. Os mais elevados percentuais de positividade ocorreram na classe etária de cinco a 14 anos, 77\% (14/ 18), e em adultos jovens, 100\% (20/20), em 1992 e 1993, respectivamente. Os menores índices foram obtidos na faixa etária de zero a quatro anos, 31\% (6/19), e 45\% (9/20) em anos consecutivos (Tabela 1).

Em 1992, a detecção de anticorpos IH para a cepa B/Yamagata/ 16/ 88 alcançou nível de positividade de $16 \%$ (13/82). Por outro lado,

\section{Tabela 2}

Freqüência dos títulos de anticorpos $\mathrm{IH}$, por um ano, para os vírus $\mathrm{A} / \mathrm{Taiwan} / 1 / 86$, A/Beijing/353/89 e B/Yamagata/16/88.

\begin{tabular}{|c|c|c|c|c|c|c|}
\hline \multirow[t]{2}{*}{ Cepa } & \multicolumn{2}{|c|}{ A/Taiwan } & \multicolumn{2}{|c|}{ A/Beijing } & \multicolumn{2}{|c|}{ B/Yamagata } \\
\hline & 1992 & 1993 & 1992 & 1993 & 1992 & 1993 \\
\hline \multicolumn{7}{|c|}{ Recíproca do Título } \\
\hline$t<20$ & 13 & 18 & 36 & 23 & 69 & 46 \\
\hline $20 \leq t<40$ & 12 & 05 & 22 & 22 & - & 18 \\
\hline$t \geq 40$ & $57 *$ & $74 *$ & 24 & $52^{*}$ & $13^{*}$ & $33 *$ \\
\hline Total & 82 & 97 & 82 & 97 & 82 & 97 \\
\hline
\end{tabular}

$P<0,05$

em 1993, obtiveram-se 52\% (51/97) de prevalência, destacando-se os adultos jovens com $75 \%$ (15/20) das amostras positivas. Na classe de zero a quatro anos observaram-se taxas de positividade comparáveis de $16 \%$ (3/19) e 20\% (4/20) em 1992 e 1993, respectivamente (Tabela 1).

Ressalte-se, porém, que a análise estatística das amostras positivas, para as três cepas previamente descritas, não revelou diferenças estatisticamente significativas, se comparados os índices de soropositividade em relação aos anos; aliás, fato também constatado entre as faixas etárias ( $p>0,05)$.

Na Tabela 2, concernente à freqüência de títulos, verifica-se que, entre os soros positivos para as três cepas, em cada ano pesquisado, a presença de anticorpos IH com títulos maiores ou iguais a 1/40 foi estatisticamente significante $(p \varangle 0,05)$, excetuando-se a cepa A/Beijing/353/ 89 (H3N2) em 1992. 
Figura 1

Prevalência de anticorpos IH de acordo com os títulos, para os vírus A/Taiwan/1/86 (H1N 1) em soros

de um segmento populacional de Belém, distribuídos por faixa etária, nos anos de 1992 e 1993.

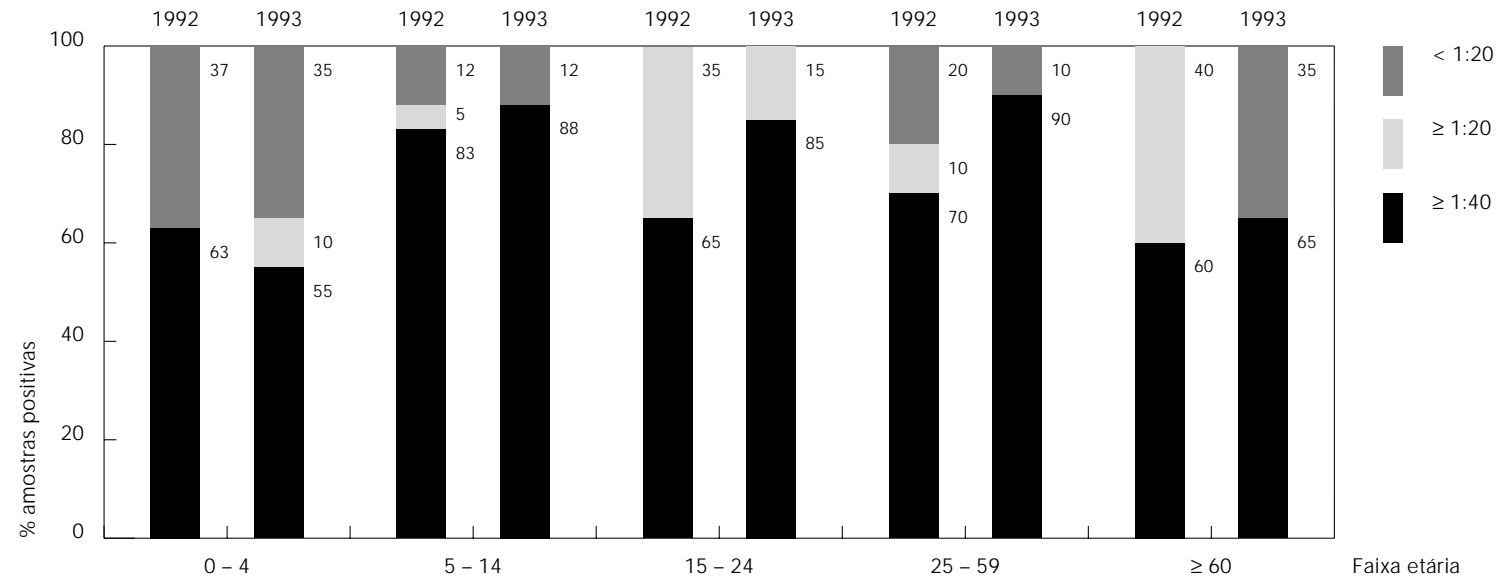

Figura 2

Prevalência de anticorpos IH de acordo com os títulos, para os vírus A/Beijing/353/89 (H3N2) em soros de um segmento populacional de Belém, distribuídos por faixa etária, nos anos de 1992 e 1993.

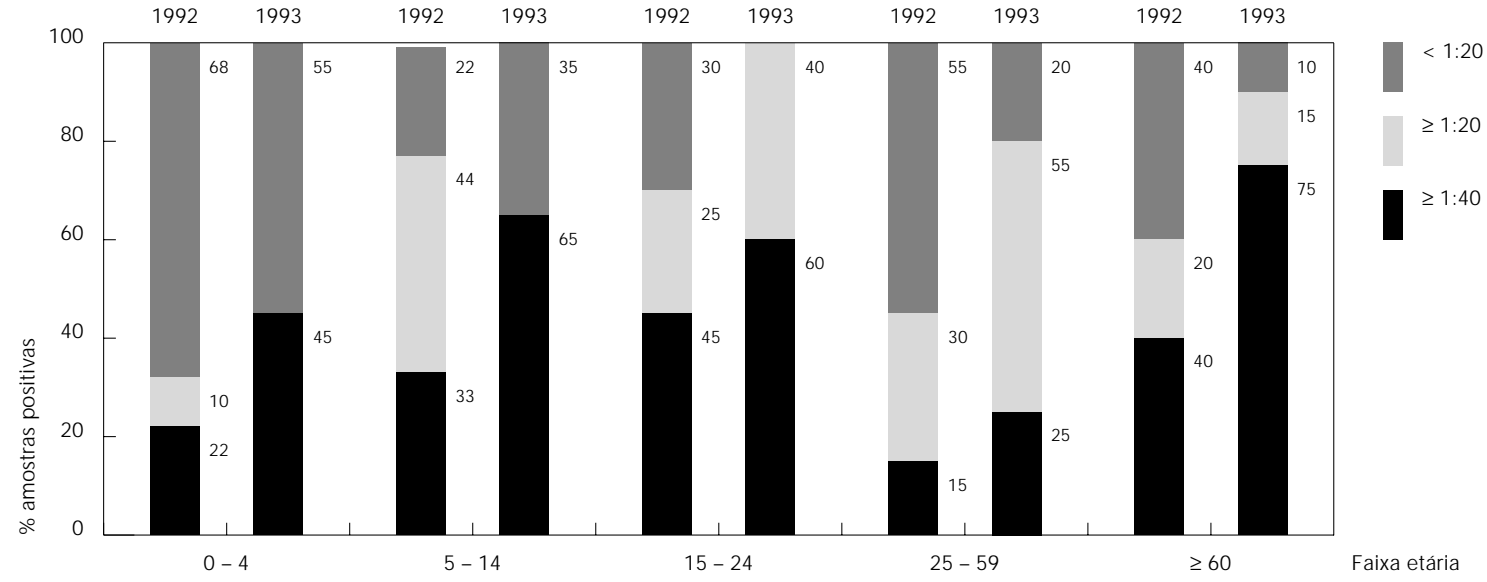

Os resultados positivos ao teste de $\mathrm{IH}$, com títulos maiores ou iguais a $1 / 40$ para A/Taiwan/ 1/ 86 (H1N1), foram evidenciados em todas as idades, nos dois anos de estudo (Figura 1).

As respostas imunes em anticorpos $\mathrm{IH}$, maiores ou iguais a $1 / 40$, para a cepa A/Beijing/353/ 89 (H3N2), foram obtidas em todas as faixas etárias, predominando, porém, em 1993. Em 1992, amostras com títulos maiores ou iguais a $1 / 20$ e menores que $1 / 40$ foram detectadas em todos os grupos etários. Em 1993, perfil de imunidade similar foi observado ape- nas nas três classes acima de 14 anos de idade (Figura 2).

Amostras positivas ao teste de IH, com títulos maiores ou iguais a 1/ 40 para B/Yamagata/ 16/ 88, foram detectadas em todos os grupos etários, mais freqüentemente em 1993 do que em 1992. Em menor escala, amostras de soro apresentaram títulos maiores ou iguais a 1/20 durante 1993 (Figura 3). 


\section{Figura 3}

Prevalência de anticorpos IH de acordo com os títulos, para os vírus B/Yamagata/16/88 em soros de um segmento populacional de Belém, distribuídos por faixa etária, nos anos de 1992 e 1993.

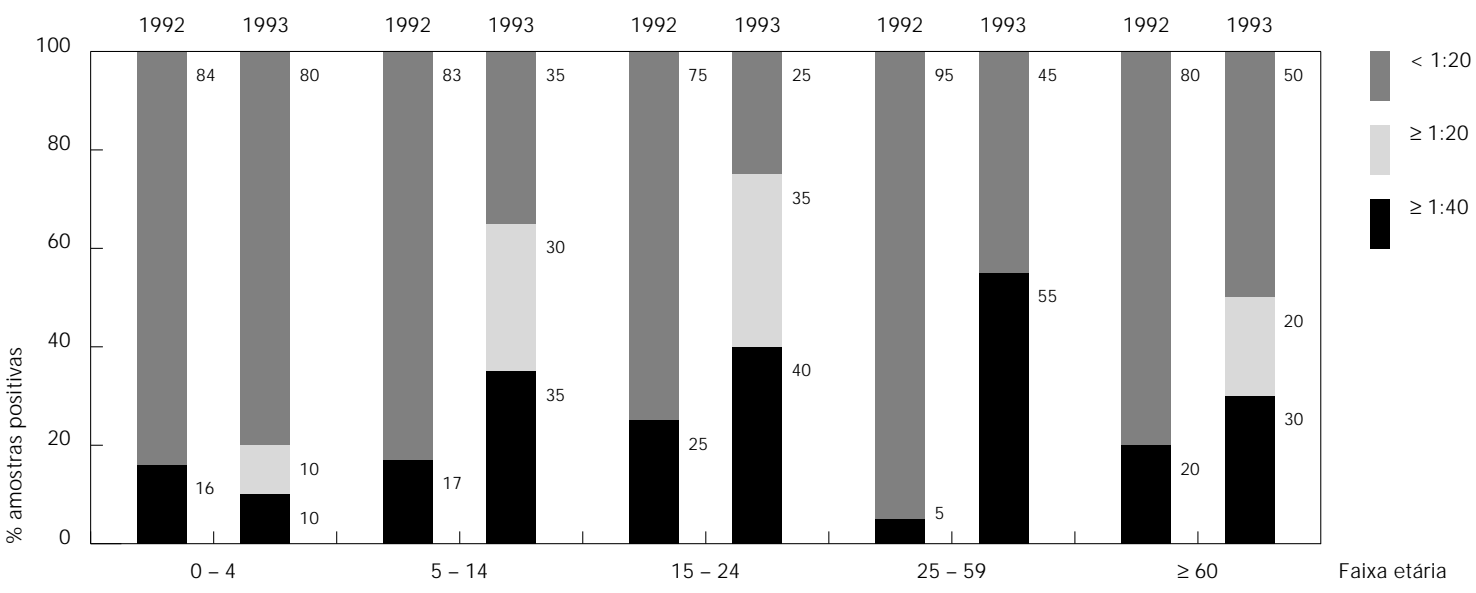

\section{Discussão}

Elevadas taxas de prevalência de anticorpos IH para influenza HIN 1 foram registradas em todas as faixas etárias durante a realização do presente estudo. Os títulos superiores ou iguais a 1/ 40 predominaram, sendo mais freqüentes com o avançar da idade, o que está de acordo com os achados de Glezen et al. (1991). Estes últimos se baseiam na ação da "doutrina do pecado original": resposta imune secundária decorrente de experiência antigênica anterior com cepas de mesmo subtipo viral.

Os resultados, de modo geral, sugerem que a população sob estudo, além do contato recente com uma cepa antigenicamente relacionada à A/Taiwan/ 1/86, foi previamente afetada por surtos ocasionados por outras variantes antigênicas de influenza H1N1.

A resposta sorológica para influenza H3N2 revelou percentuais el evados e crescentes de um ano para outro: 56\% em 1992 e 76\% em 1993. Embora em nosso estudo os menores índices de positividade para tais vírus tenham sido detectados na faixa etária de zero a quatro anos, Sugaya et al. (1992) ratificam esses patógenos como causa importante de hospitalização infantil. Por outro lado, entre os adultos de sessenta anos ou mais, detectaram-se prevalências elevadas para influenza H3N2, cuja circulação tem sido fortemente relacionada com o aumento das taxas de morbidade e mortalidade nesse grupo etário (Lui \& Kendal, 1987; Sprenger et al., 1990).
As amostras positivas para a cepa A/Beijing/353/ 89 não exibiram distribuição predominante de positividade para determinada faixa etária. Contudo, a expressiva detecção $(p<0,05)$ de títulos maiores ou iguais a $1 / 40$ sustenta a circulação desta cepa (ou de uma antigenicamente relacionada a ela), durante 1993.

A influenza B ocorreu moderadamente em 1992, assemelhando-se aos resultados obtidos em Cuba por Estupiñón et al. (1986). Entretanto, em 1993, obteve-se o triplo de positividade no que concerne à freqüência de anticorpos. Apesar de prevalências moderadas terem sido obtidas para a cepa B/Yamagata/ 16/ 88 entre os menores de zero a quatro anos, estes vírus são comumente associados à necessidade de hospitalização infantil (Sugaya et al., 1992).

As respostas positivas para influenza B/Yamagata/ 16/88, nos dois anos estudados, não indicaram predomínio expressivo em determinada faixa etária. No entanto, a ocorrência de títulos maiores ou iguais a $1 / 40$, com diferenças estatisticamente significativas em relação aos demais, sugere o contato recente com tal cepa ou com outra antigenicamente relacionada, principalmente em 1993.

De modo geral, este estudo demonstrou uma distribuição relativamente homogênea dos vírus da influenza $A$ e $B$ em todas as idades, ao longo dos anos. Em 1992, revelou-se expressiva circulação dos subtipos da influenza $A$, bem como moderada atividade dos vírus $\mathrm{B}$. Em 1993, por outro lado, prevalências elevadas, expressas por títulos superiores ou iguais a $1 / 40$, 
indicaram intensa propagação dos vírus da influenza A e B.

Os resultados do presente trabalho estão de acordo com aquele assinalado pelo "Centers For Disease Control and Prevention - CDCP" (1992-1993), no que tange à circulação dessas cepas virais no mundo. Segundo o CDCP, o caráter epidêmico foi relacionado, sobretudo, ao subtipo H3N2 (A/Beijing/353/89). No entanto, o H1N 1 (A/Taiwan/1/86) foi identificado em 17 países e responsabilizado por surtos autolimitados. A cepa influenza B/Yamagata/ 16/88, por sua vez, produziu surtos em alguns países europeus, asiáticos e nos Estados Unidos da América do Norte, muito embora tenha ocorrido em níveis moderados em outras regiões.

O número limitado de amostras analisadas não possibilita avaliar a circulação dos vírus da influenza entre a população de Belém. Contudo, o contigente de pacientes estudados refe-

\section{Agradecimentos}

Ao Dr. Alexandre da Costa Linhares por suas valiosas sugestões à redação deste estudo, a Arno Hamel por sua significativa colaboração na análise estatística, a Olinda Macedo e a Ana Cecília Ribeiro Cruz por sua presteza na elaboração dos gráficos. rente à demanda ao serviço médico de Virologia do IEC, nos meses de novembro-dezembro dos anos de 1992 e 1993, é representativo, o que permite aferir a circulação epidêmica de cepas virais antigenicamente relacionadas nesse segmento populacional, no transcorrer dos referidos anos.

Em virtude das características peculiares da influenza, as medidas de prevenção e controle sustentam a necessidade, em nível local, da caracterização sistemática dos sorotipos endêmicos, de programas seletivos de imunização, bem como de estudos clínico-epidemiológicos. Estes últimos visam a aferir a morbi-mortalidade inerente à infecção pelo vírus influenza em Belém, uma vez que não se sabe como se comportarão os futuros surtos da influenza no tocante à extensão e severidade clínica. Nesse sentido, é imperativo manter-se vigilância epidemiológica contínua, quer pelo isolamento viral, quer pela análise sorológica.

\section{Referências}

CANDEIAS, J. N. N. \& PEREIRA, M. S., 1972. The measurement by serological means of the impact of the Hong Kong/ 68 influenza virus on a population. Revista deSaúdePública, 6:85-88.

CDC (Centers for Disease Control and Prevention), 1991. Influenza Virus Reagents for the Hemagglutination Inhibition Test. Atlanta: CDC.

CDC (Centers for Disease Control and Prevention), 1992-1993. Epidemiology and Control of Influenza in CDC. Atlanta: CDC.

CHAKRAVERTY, P., 1980. Comparison of haemagglutination inhibition and single radial haemolysis techniques for detection of antibodies to influenza B virus. Archive of Virology, 63:285-289.

CHAKRAVERTY, P.; CUNNINGHAM, P.; SHEN, G. Z. \& PEREIRA, M. S., 1986. Influenza in the United Kingdom, 1982-1985. Journal of Hygiene, 97:347358.

ESTUPIÑON, F. A.; MURCIA, P. G. \& MARTELL, A. E. O., 1986. Estudio sorológico de los virus de influenza. Información previa. Revista Cubana de Hygieney Epidemiología, 24:31-40. 
GLEZEN, W. P.; KEITEL, W. A.; TABER, L. H.; PIEDRA, P. A.; CLOVER, R. D. \& COUCH, R. B., 1991. Age distribution of patients with medically-attended illnesses caused by sequential variants of influenza A/H1N1: comparison to age-specific infection rates, 1978-1989. American Journal of Epidemiology, 133:296-304.

JENNINGS, R.; SMITH, T. L.; MELLERSH, A. R.; CLARK, A.; SPENCER, R. C. \& POTTER, C. W., 1985. Antibody response and persistence in volunteers following immunization with varying dosages of a trivalent surface antigen influenza virus vaccine. Journal of Hygiene, 94:87-95.

LUI, K. J. \& KENDAL, A. P., 1987. Impact of influenza epidemics on mortality in the United States from October 1972 to May 1985. American Journal of Public Health, 77:712-716.

McGREGOR, I. A.; SCHILD, G. C.; BILLEWICZ, W. L. \& WILLIAMS, K., 1979. The epidemiology of influenza in a tropical (Gambian) environment. British Medical Bulletin, 35:15-22.

SPRENGER, M. J. W.; DIEPERSLOOT, R. J. A.; BEYER, W. E. P. \& MASUREL, N., 1990. Influenza-related excess mortality in the Netherlands 1989/90. The Lancet, 11:382.
STUART-HARRIS, C. H., 1979. Epidemiology of influenza in man. British Medical Bulletin, 35:3-8.

SUGAYA, N.; NEROME, K.; ISHIDA, M.; NEROME, R.; NAGAE, M.; TAKEUCHI, Y. \& OSANO, M., 1992. Impact of influenza virus infection as a cause of pediatric hospitalization. Journal of Infection and Disease, 165:373-375.

TAKIM OTO, S.; CARVALHO, R. P. S.; PEREIRA, H. G.; PANNUTI, C. S.; PEREIRA, M. S. \& SALLESGOMES, L. F., 1986. Serologic studies on the behavior of influenza virus type $A$ in persons of great São Paulo during 1976, 1978 and 1979. Revista do Instituto de Medicina Tropical deSão PauIo, 28:413-420.

WOOD, J. M.; GAINES-DAS, J.; TAYLOR, J. \& CHAKRAVERTY, P., 1994. Comparison of influenza serological techniques by international collaborative study. Vaccine, 12:167-174.

ZUCKERM AN, M. A.; WOOD, J.; CHAKRAVERTY, P.; TAYLOR, J.; HEATH, A. B. \& OXFORD, J. S., 1991. Serological responses in volunteers to inactived trivalent subunit influenza vaccine: antibody reactivy with epidemic influenza $A$ and $B$ strains and evidence of a rapid immune response. Journal of Medical Virology, 33:133-137. 